\title{
Using Augmented Reality to engage STEM students with an authentic curriculum
}

\author{
Mike Hobbs and \\ Debbie Holley \\ Anglia Ruskin University \\ \{mike.hobbs, debbie.holley\} @anglia.ac.uk
}

\begin{abstract}
This paper reports on the introduction of a set of 'Augmented Reality' (AR) tasks, offering an innovative, real world and problem based set of activities for a group of first year University Gaming and Computer Science students. Our initial research identifies a gap in the perceptions of STEM students between the usefulness of discipline based modules and a compulsory 'Professional Development' module where more 'employability' based skills were delivered. It had a history of poor student engagement and attendance, and failed to provide a compelling narrative/links to the outside world. The AR tasks were designed to facilitate group-working and multi-channel communication, and to engage students through the use of a more creative technology. Framed as a rich case study, insights are captured through student blogs, video interviews and a questionnaire. Initial findings indicate higher levels of satisfaction, enhanced student engagement and a greater awareness of the value of transferable skills.
\end{abstract}

Keywords: STEM, Professional Development, Academic skills, Student engagement, Augmented Reality, BYOD

\section{Introduction}

This paper reports on the introduction of a set of creative 'Augmented Reality'(AR) tasks, offering innovative, real world and problem based activities for first year University Gaming and Computer Science students. Our initial research identifies a gap in the perceptions of STEM students between the usefulness of discipline based modules and a compulsory 'Professional Development' module where more 'employability' skills are embedded. It had a history of poor student engagement/attendance, and failed to provide a compelling narrative.

The extensive review of the literature of augmented reality (AR) by Carmigniani and Furht [1] provides a taxonomy of systems and applications, including education. In common with most analysis of AR they focus on how systems deliver content and an interactive, context aware, experience for the user. Since the introduction of AR (1990s) [2] augmented reality systems have been used in many areas of education, including higher education [3] and STEM subjects such as maths [4] and physics [5] Yuen et al [6] suggested five directions for AR in education - books, gaming, 
discovery based learning, object modelling and skills training. Each area benefits from the context sensitive delivery of interactive material that can enhance an essentially 'real world', authentic experience. Concluded their overview they noted: "... most current educators will find that, while it is possible for them, as individuals, to create AR content using the tools mentioned earlier in this paper, truly userfriendly AR creation tools may still be just over the horizon."

While this is probably still true for the more sophisticated AR experiences, there is a significant sub-set of simple AR application creation tools that allow those with limited technical ability to become AR creators. These newer, user friendly technologies [7] have combined with the rise of smartphone usage [8] to enable the majority of students to access educational AR applications via their own device. Our study is located within the user-generated content of SMART devices, in that our students are creating their own artefacts using the Aurasma AR 'App'.

\subsection{Theoretical context for AR}

The theoretical basis for AR in education can be seen as an extension to the Cognitive Theory of Multimedia Learning that suggests images/other media give more impact to the learning experience. However, in this study we focus on the use of ARas a creative tool We aim to harness the process of creating AR to provide a context for a range of higher education skills within a Collaborative Learning (CL) framework. A systematic review of the literature in computer supported CL by Shawkey et. al. [9] shows AR as one of several computer systems that can be used to facilitate CL and this view is confirmed by Lin et. al. [10].

Collaborative Learning is based on the idea that students learn as much, or more, from each other than they do from an instructor - this is particularly relevant to higher education where it is expected that the majority of the work is done by the student outside of the lecture theatre. Vygotsky's theories of learning as a social, constructivist process [11], where individuals establish a shared view of a problem and how to solve it, underpins CL and offered useful insights into the design of the revised set of student tasks[12][13]. By utilising mobile student devices learning can take place at a time and virtual / physical location and time of the students choosing and offers the advantages of more personalised learning across multiple platform, both personal and institutional[14].

\subsection{The Case Study Approach}

Drawing upon [15] Stake (1983) we see this case study as a rich case in its own right: comparing and contrasting our student groups feedback offers a rich and deep analysis. Case studies offer insights into both what is common and particular about a case, and a uniqueness that Stouffer [16] refers to as pervasive, extending to factors such as the nature of the case, historic setting, physical context, cases through which this case is recognised and those informant through whom the case can be known. Thus for a complex and nuanced case, looking at our students through this lens offers the advantages of multiple data collection tools, Institutional documents; field notes 
from the researchers during the process of the intervention; student blogs and video focus groups analysis all that offers insights into the students sense of meaning making after the event as they reflect upon their experiences [17].

\subsection{Method}

12 sets of 'small focus group' interviews were conducted obtain early feedback. Conducted in class, this modelled to students how they could get user feedback from their own projects later in the course. All participants took part voluntarily and were aware that participation/ non- participation would not have any impact on their marks. The researcher was introduced as a member of staff from the Education department, interested in team work and technology projects.

The focus groups were filmed and permission gained for edited clips to be embedded within our own project website and for dissemination purposes. For data transcription purposes, each student had a 'number' placed in front of him/her, to enable accurate analysis. The course tutor led on the filming, and coached different members of the class in how to film as the focus groups took place, thus assisting students to develop another skill to add to their PDP.

Institutional documentation; field notes from both authors; video analysis; blog postings and in class artefact showcasing all contribute to this case study.

\section{The Augmented Reality 'mini' project}

\subsection{Soft Skills for STEM Students}

It is particularly difficult to get technically motivated students from STEM disciplines to consider the softer skills, even when they are aware that these are desired by employers and are likely to be the differentiating factor in recruitment between equally technical applicants. Within the perceived context of a lack of STEM graduates, there is a significant problem that too many lack the soft skills to enable them to be ready for work [18]. Other studies have shown that there is a gap between what companies want in terms of skills, and what is provided by higher education institutions; with communication skills and independent problem solving being identified [19][20].

The Personal Development Planning (PDP) is a common element in most UK Higher Education as Universities are required to provide a transcript to record their learning and achievement and a process by which they can monitor, build and reflect on their development[21][22]. Key aspects of this are for students to become more independent, adopt a pro-active approach to their study, extra-curricular pursuits and career planning. In addition to these principles the PDP for first year students in Computer Science and Computer Gaming Technology degrees includes an introduction (or reminder) of basic academic skills. This has traditionally been delivered through a series of one hour tutor led classes/lectures on topics such as: 
Self-Evaluation Exercise, Note Taking, Group Work, Presentations, Library and referencing Skills, Report Writing, Keeping a Log Book, Time Management, Submitting Work, Plagiarism and the creation of the PDP portfolio.

End of year Course Reviews identified issues of poor engagement with the module, seen in low pass rates and tutors comments on lack of attendance. Despite the tensions of delivering a STEM curriculum with a high discipline based content, students clearly needed the 'softer skills' developed through this module. Thus a redesign was needed, and a more creative approach considered [23].

\subsection{Why AR?}

Media interest in AR and application framework development had a surge of activity in 2012, but to some extent AR is regarded as a solution in search of a problem [24]. However, although wider commercial applications remain elusive it has been seen as a promising area for education [25][26].

Our students were aware of AR but had little experience apart from a few who had played AR games. At all times care was taken that if a student did not wish to engage with the AR mini project they would still be able to complete their PDP tasks and would not be disadvantaged.

AR systems such as Aursama [27] are ultimately financed by revenue generated from advertising/commercial applications. However, to boost user numbers they encourage individual creation of $\mathrm{AR}$ artefacts through free user accounts. An advantage of Aurasma is that it allows the complete AR creation process to be carried out on a mobile device with the freely available app (iOS and Android). The Aruasma app runs on a mobile device and uses the camera viewfinder to recognise a trigger image. Once trigged an 'Aura' (i.e. the pre-recorded media) can be viewed on the screen of mobile device. We utilised a 'Bring Your Own Device' (BYOD) model, which included all students even if they did not own a SMART device.

\subsection{Project Design and Tasks}

Previous studies [28] showed the value of using an interesting and inherently engaging technology (in that case a Virtual World) to facilitate group work and to promote broader skill acquisition. Then, as now, ability with the technology was secondary to the development of the skills needed to achieve the tasks.

Student brief: Self-selecting into small groups of 3/5 groups were asked to create a name and logo and to engage with the University Library, in the broadest sense, by producing an AR artefact. They were encouraged to plan, script and story board their short video. Apart from asking them to observe the intellectual property rights of images, videos and music, students were free to create their own videos. Weekly sessions were used for feedback, discussion and introducing the supporting materials on the VLE. Additional support was offered through email, discussion boards and comments posted on blog sites. Groups were asked to do a short $5 \mathrm{~min}$ presentation to 
the class. Most demonstrated reasonable presentation skills; in many cases showed considerable independent research around the topic. Because they were all related to the same topic students found it easy to ask questions; this promoted lively debate. Time/project management were demonstrated by group meetings and task allocations.

\section{Evaluation}

Table 1. Results from interview sessions.

\section{(id) Group working style \\ (1) Worked as a group on the project,} meeting in the library.

\section{Student comments}

"It's very, very simple to use. It goes through everything that you need to know to create an aura."

"The beauty of it was that we were able to email each other as it was a very technology-based thing." a point of contact.

Some previous experience with AR, happy to do more with this project.

(3) Worked individually and as a group, used Facebook as point of contact.

(4) Used Watsapp and the blog to communicate, worked together and visited the library. Made some progress with the project.

(5) Worked together as a group. Also made an aura from signs at the college.

(6) Used Skype and Facebook to communicate with regular face to face meetings. Posed to the blog as a group and individually.

(7) Well organised group

Had problems but managed to create an aura.

(8) The group used the blog but also set up a Facebook page and website. Created a logo and group name.

(9) Group met up regularly, communicated through Skype /

Facebook and in person. Created a group name and a logo and attached some books related to the course.
"I first heard about it, I think it was 2011, demonstrated on an iPad."

"We found a book about sports which had an aura of somebody doing weightlifting."

"We went for a book that stood out and that didn't have a plain background."

Made aura for a book on confidence: "We decided that this [the book] was relevant for this kind of PDP course."

"It's been challenging but we've overcome it."

"We tried to find a decent trigger image that isn't too widely used and doesn't conflict with copyright."

"For some reason the university computers just won't pick it up but we've tried our own tablets and it know what's going on." works absolutely fine so we don't 
(10) Worked together and Facebook chats to communicate but already knew each other.

(11) Used Facebook/ Steam to communicate as well as face-to-face meetings. Aurasma app was easy to use.

(12) Met as a group but somewhat disorganized. 1 student made an aura and displayed it on their phone and had updated a blog.
They found the Aurasma app very easy to use "If you follow the instructions, anyone could do it."

The group task was commented on as "It's a bit of a pain but it will help"

"When I first came to university I

didn't know anybody. To be put into a group to meet people is quite nice."

\subsection{Emergent themes from the project}

- Groups that met up in person seemed to achieve significantly more than those groups which used online communication exclusively.

- The subject of the project, developing AR artefacts for library purposes, did not seem to inspire them, although it did make them visit the library.

- Students could see the worth of cooperation and recording what they did so that the project could progress.

- For the tutors, working with an authentic task offered something concrete to relate abstract notions of academic skills

- Novelty of application helped the groups working as there was no 'expert'.

All the participants were keen video game players and very proud of their choice of course - many had selected it specifically because of the core element of 'hard' programming with 'most' programming modules. This is seen as a key element of obtaining work in the gaming industry, and two students, from an arts and music background, highlighted the programming course element before disclosing their extremely exceptional skills in a different area.

They did not value the PDP module as highly as other 'programming' modules, but when prompted, did acknowledge the value for employment. Some groups already knew one another but for others it was a good way to make contact with fellow students at an early part of their course. The groups communicated in very different ways (see table 1). Most groups reported a technical/communication issues that they had to overcome by researching their own solution. So despite a relatively easy set of well scaffolded tasks students reported a genuine sense of achievement which contributed to confidence and independence.

\section{Conclusions}

Developing user-generated content for the PDP course worked well, and the selection of AR offered the students the opportunity to learn about an interesting subject. There was a marked improvement in performance between this cohort and the previous PDP 
results. Non submission improved from $34 \%$ (in a cohort of 55) to $22 \%$ (in a cohort of 78). The PDP is a pass/fail element attached to a larger module that teaches game engine technology. The change in those who engaged with the PDP is even more marked when you consider that in $2013 / 14,15 \%$ who submitted the main assessment but did not bother with PDP, but in 2014/15 there was actually one more student who submitted to PDP than for the main assessment.

Our case study has provided some interesting findings about STEM students and their engagement with 'softer skills'. With such a small study, it is not possible to generalise the findings, however, we have been able to identify some key features to be incorporated for the PDP design for the next iterations.

The first is to have a greater focus around team work and a clearer structure. The students interviewed were unfamiliar with group work of any kind. This because obvious in the interviews where many of the groups seemed clueless when they were asked about task progression. Secondly, as tutors, we need to model and scaffold teamwork in a more overt and clear way.

Finally, we are keen to provide more opportunities to practice communication. When interviewed a significant minority of the students struggle to make eye contact, hold a conversation and speak eloquently about a subject. Preparing and giving presentations in a supportive environment is an excellent way of developing these skills.

We would like to acknowledge the work of Mathew Scofield (researcher) for assistance with the data analysis.

\section{References}

1. Carmigniani, J., \& Furht, B.:Augmented reality: an overview. In Handbook of augmented reality (pp. 3-46). Springer New York (2011)

2. Azuma, R. T.: A survey of augmented reality. Presence-Teleoperators and Virtual Environments, 6 (4), 355 - 385 (1997)

3. Liarokapis, F. and Anderson, E.F.: Using augmented reality as a medium to assist teaching in higher education.Proc. of the 31st Annual Conference of the European Association for Computer Graphics (Eurographics 2010), volume Education Program : 9-16 (2010)

4. Kaufmann, H., \& Schmalstieg, D.:Mathematics and geometry education with collaborative augmented reality.Computers \& Graphics, 27(3), 339-345 (2003)

5. Ibáñez, María Blanca, et al.: Experimenting with electromagnetism using augmented reality: Impact on flow student experience and educational effectiveness. Computers \& Education71: 1-13 (2014)

6. Yuen, S., Yaoyuneyong, G., and Johnson, E.: Augmented reality: An overview and five directions for AR in education. Journal of Educational Technology Development and Exchange4.1 : 119-140 (2011)

7. EdTechReview on Augmented Reality [Online] http://edtechreview.in/trendsinsights/insights/1503-teaching-with-augmented-reality-it-s-here (2015)

8. UCAS media.: Eight out of Ten Freshers have Smartphones (2014)

9. Shawky, D., Said, T., Badawi, A., Hozayin, R.: Affordances of computer-supported collaborative learning platforms: A systematic review, Interactive Collaborative Learning 2014 International Conference pp.633,651. doi:10.1109/ICL.2014.7017846 (2014)

10. Lin, T, Duh, H., Li, N., Wang, H., Tsai, C.: An investigation of learners' collaborative knowledge construction performances and behavior patterns in an augmented reality 
simulation system, Computers \& Education, Volume 68, October 2013, Pages 314-321, ISSN 0360-1315, http://dx.doi.org/10.1016/j.compedu.2013.05.011 (2013)

11. Vygotsky, L.S. (1978). Mind in Society. The development of higher psychological processes (Cole, M., Ed.). Cambridge MA: Harvard University Press (Original work published 1930) (1978)

12. Lee, C.D. and Smagorinsky, P.; Vygotskian perspectives on literacy research: Constructing meaning through collaborative inquiry. Cambridge, England: Cambridge University Press (2000)

13. Cook, J.: Mobile phones as mediating tools within augmented contexts for development. International Journal of Mobile and Blended Learning, 2(3), 1-12. http://goo.gl/NFWnSZ $\underline{(2010)}$

14. Kukulska-Hulme, A., Traxler, J., and Pettit, J.: Designed and user-generated activity in the mobile age. Journal of Learning Design, 2(1) pp. 52-65 (2007)

15. Stake, R.E.: The case study method in social inquiry. Evaluation models. Springer Netherlands, pp. 279-286 (1983)

16. Stouffer, S. A.: "Notes on the case-study and the unique case". Sociometry, 349-357,1941. Regional studies, 39(1), 61-74 (2005)

17. Kress, Gunther.: Design and Transformation: New Theories of Meaning. Pp. 153-161 in Multiliteracies: Literacy Learning and the Design of Social Futures, edited by Bill Cope and Mary Kalantzis. London: Routledge. pp. 155-156, 158 (2000)

18. CBI/Pearson: Changing the pace - Education and Skills Survey (2013)

19. Harris, M.: STEM paradox, is there really a shortage of STEM graduates in the workplace? Physics World.(2014)

20. UKCES: The Labour Market Story: Skills for the Future, briefing paper 2014, UK Commission for Employment and Skills. (2014) https://www.gov.uk/government/uploads/system/uploads/attachment_data/file/344441/The Labour_Market_Story-_Skills_for_the_Future.pdf

21. Houghton, W., Maddocks, A.: Personal Development Planning for Engineering Students, Higher Education Academy, Engineering Subject Centre (2005)

22. QAA: Recognising achievement beyond the curriculum (2013) http://www.qaa.ac.uk/assuring-standards-and-quality/skills-for-employability

23. Holley, D., Hobbs, M., Howlett, P. and Sawyerr, W.: The chaotic science lab': supporting trainee Science teachers a cross-departmental project. Anglia Ruskin University Networks, 16, pp.51-- 58 (2013) http://hdl.handle.net/10540/303566

24. Dunleavy, M., \& Dede, C.: Augmented reality teaching and learning. In J. Spector, M. Merrill, J. Elen, \& M. Bishop (Eds.), The handbook of research for educational communications and technology (pp. 735 - 745). New York: Springer (2014)

25. Lee, K.: Augmented Reality in Education and Training, TechTrends March 2012, 56:2, pp12-21 (2012)

26. Johnson, L., Adams Becker, S., Estrada, V., Freeman, A.: NMC Horizon Report: 2014 Higher Education Edition. Austin, Texas: The New Media Consortium.NMC 2014. NMC Horizon Report Higher Education. (2014) http://cdn.nmc.org/media/2014-nmc-horizonreport-he-EN-SC.pdf

27 Aursasma: Aurasma website, HP software, (2015) http://www.aurasma.com

28. Brown, E., Gordon, M., Hobbs, M.: Second Life as a holistic learning environment for problem-based learning and transferable skills. Assessment 2008 39-48. 